\title{
A Numerical Study on Premixed Bluff Body Flame of Different Bluff Apex Angle
}

\author{
Gelan Yang, ${ }^{1}$ Huixia Jin, ${ }^{2}$ and $\mathrm{Na} \mathrm{Bai}^{3}$ \\ ${ }^{1}$ School of Information Science and Engineering, Hunan City University, Yiyang 413000, China \\ ${ }^{2}$ School of Electronics and Communications Engineering, Hunan City University, Yiyang, China \\ ${ }^{3}$ School of Electronics and Information Engineering, Anhui University, Hefei, China \\ Correspondence should be addressed to Gelan Yang; glyang@mail.ustc.edu.cn
}

Received 21 October 2012; Revised 28 January 2013; Accepted 28 January 2013

Academic Editor: Zhijun Zhang

Copyright (C) 2013 Gelan Yang et al. This is an open access article distributed under the Creative Commons Attribution License, which permits unrestricted use, distribution, and reproduction in any medium, provided the original work is properly cited.

\begin{abstract}
In order to investigate effects of apex angle $(\alpha)$ on chemically reacting turbulent flow and thermal fields in a channel with a bluff body V-gutter flame holder, a numerical study has been carried out in this paper. With a basic geometry used in a previous experimental study, the apex angle was varied from $45^{\circ}$ to $150^{\circ}$. Eddy dissipation concept (EDC) combustion model was used for air and propane premixed flame. LES-Smagorinsky model was selected for turbulence. The gird-dependent learning and numerical model verification were done. Both nonreactive and reactive conditions were analyzed and compared. The results show that as $\alpha$ increases, recirculation zone becomes bigger, and Strouhal number increases a little in nonreactive cases while decreases a little in reactive cases, and the increase of $\alpha$ makes the flame shape wider, which will increase the chamber volume heat release ratio and enhance the flame stability.
\end{abstract}

\section{Introduction}

Flames can only be stabilized in high-velocity reactant streams over a certain range of conditions, while a variety of approaches are used to stabilize flames in a combustor, for example, bluff body flame holders such that $\mathrm{V}$ gutters are widely used in many modern combustion devices, such as augmenters or after burners in turbojet/turbofan engines and ramjet engines [1]. Combustors with bluff-body flame holders are characterized by a shear layer where vortices are shed due to Kelvin-Helmholtz instability [2], and this shear layer separates the region of high-speed fresh mixtures from the wake region of lower-speed hot products, and due to the boundary layer separation, a V-gutter bluff body creates a recirculation zone that acts as an ignition source for incoming fuel/air mixture by recycling hot products and radicals from the burned mixture.

Both experimental and numerical studies on bluff body flame have been done over years. Fujii et al. [3] and Yue et al. [4] carried out experiments to study nonreactive flow without reaction characteristics behind a flame stabilizer. Nakamura
[5] studied vortex-shedding frequency of bluff bodies with different after-body shape, his study showed that Strouhal number increases as the ratio of afterbody length to crossflow dimension of the bluff body is increased. Sanquer et al. [6] investigated the chemically reacting flow characteristics behind V gutters. Cuppoletti et al. [6] measured the highfrequency combustion instabilities with a radial $\mathrm{V}$ gutter. Sjunnesson et al. $[7,8]$ used LDA and CARS measuring the velocities and turbulence in a bluff body stabilized flame and describe the rig in detail and report preliminary computations of the flow field using a two-step global mechanism solved online with Arrhenius expressions in conjunction with the Magnusen-Hjerthager combustion model. Siewert [9] studied the methane/air premixed flames at high pressure using PIV and OH PILF. In numerical field, Eriksson [10] carried out numerical study of different RANS turbulence models efferent on rig VR-1 flame using CFD software CFX based on Zimont Turbulent Flame Closure (TFC) model, but they did not discuss LES model and vortex shedding. Engdar et al. [11] apply the Level-Set Flamelet Library approach in conjunction with varying 2-equation turbulence models, 


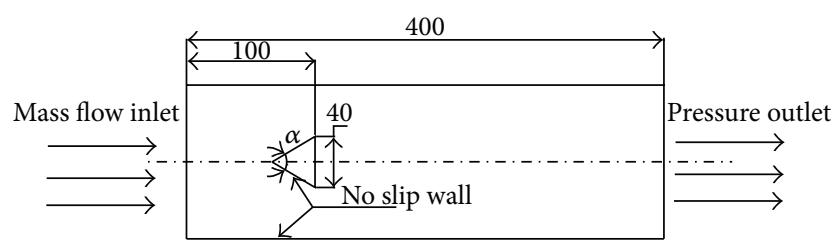

FIGURE 1: Geometry structure and boundary condition of bluffbody.

flame speed models, and flame thickness models. 50 species and 402 elementary reactions were used to build the flamelet library. Giacomazzi et al. [12] used the fractal model as SGS model of LES for turbulence and EDC combustion model to compare experiment dates of VR-1 with LES-FM, RANS k- $\varepsilon$, and LES-Smagorinsky model. Wang [13], Fureby [14], and Porumbel and Menon[15] had also performed LES computations on VR-1. Erickson and Soteriou [16] carried out numerical study on reactant temperature effect of a twodimensional triangular bluff body flame. Park and Ko [17] introduced a $G$ equation to Les subgrid scale combustion model for turbulent premixed flame stabilized by the bluff body.

Although direct numerical simulation (DNS) is able to resolve all turbulence scales, its computational resource requirements are prohibited for practical applications. In recent year, LES and hybrid RANS/LES approaches received great attentions among researchers as it can capture more transient turbulence structures than RANS for flame holder studies as discussed above. In order to investigate the bluff apex angle effects on flow field, 2D numerical study has been carried out using CFD software FLUENT 6.3.26 in this paper, EDC flame model which assumes that chemical reactions take place only at the dissipative scales of turbulence is used for premixed flame simulation. In turbulence, Smagorinsky subgrid LES model is applied.

\section{Theoretical Fundamentals of the EDC Model}

Most fuels are fast burning, and the overall rate of reaction is controlled by turbulent mixing. In premixed flames, the turbulence slowly convects/mixes cold reactants and hot products into the reaction zones, where reaction occurs rapidly. In such cases, the combustion is said to be mixing limited, and the complex chemical kinetic rates can be safely neglected. Both physical and chemical processes are important in simulating combustion systems. The formation of turbulent structures is a physical process, for which the concept of the eddy cascade model is the basis [19]. The largest turbulent structures have a size, which is of the magnitude of the system's dimensions. By interaction among themselves, eddies dissipate to smaller ones. The smallest eddies have an extension:

$$
\eta \cdot\left(\frac{v^{3}}{\varepsilon}\right)
$$

where $\eta$ is the Kolmogorov length scale. At these scales, dissipation of turbulent kinetic energy $k$ takes place with a

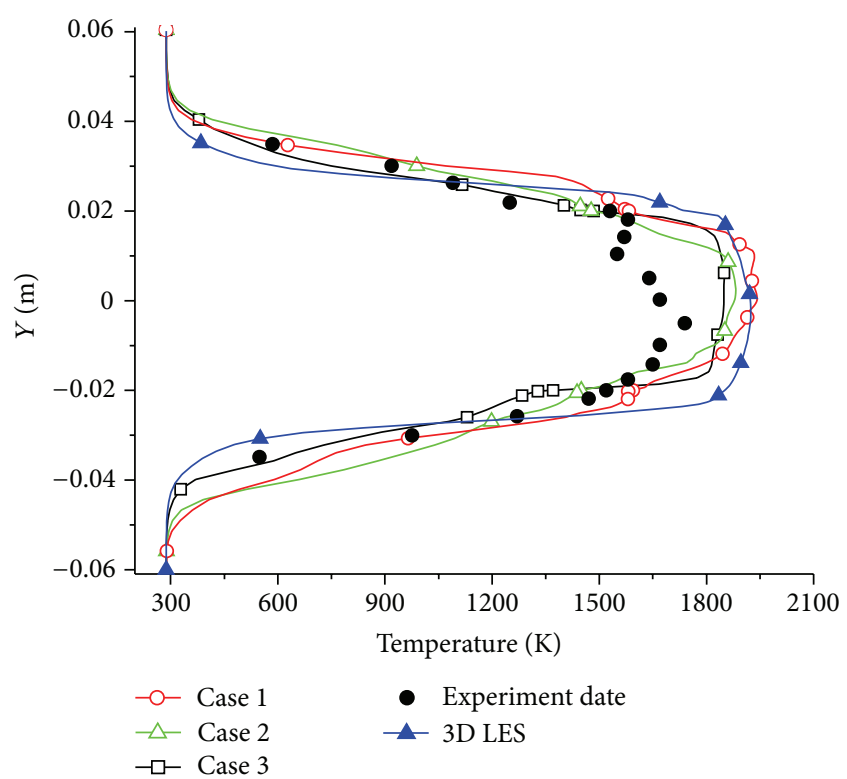

FIgURE 2: Temperature distribution at different grid sizes $(X=$ $15 \mathrm{~cm}$ ) and reaction experiment date.

rate $\varepsilon$ where $v$ is the kinematic viscosity. At a size smaller than $\eta$ no turbulent structures exist, because in those regions molecular diffusion is faster than turbulent transport. From this thought the conception of the EDC was developed. There is a range in which the reactions can be regarded as ideally mixed. Thus, chemical reaction kinetics determines the speed of the process. while outside this range the reactants are not mixed and do not react, it assumes that reaction occurs in small turbulent structures, called the fine scales. The length fraction of the fine scales is modeled as

$$
\gamma=C_{\gamma}\left(\frac{v \varepsilon}{k^{2}}\right)^{1 / 4} \quad \text { with } C_{\gamma}=2.1377
$$

The volume fraction of the fine scales is calculated as $\gamma^{3}$. Species are assumed to react in the fine structures over a time scale:

$$
\tau=C_{\tau}\left(\frac{v}{\varepsilon}\right)^{1 / 2}
$$

with $C_{\gamma}=0.4082$.

The species transport equation (conservation equation) is written as

$$
\begin{aligned}
& \frac{\partial}{\partial t}\left(\rho Y_{i}\right)+\nabla \cdot\left(\rho \vec{v} Y_{i}\right) \\
& \quad=-\nabla \cdot J_{i}+R_{i} \quad \text { with } R_{i}=\frac{\rho \gamma^{2}}{\tau\left(1-\gamma^{3}\right)}\left(Y_{i}^{*}-Y_{i}\right)
\end{aligned}
$$

The computation of the reaction rate source terms is accelerated with the in-situ adaptive tabulation (ISAT) algorithm [19] embodied in the solver. For simplicity, the propane-air combustion was simulated using a one-step irreversible chemical reaction:

$$
\mathrm{C}_{3} \mathrm{H}_{8}+5 \mathrm{O}_{2} \longrightarrow 3 \mathrm{CO}_{2}+4 \mathrm{H}_{2} \mathrm{O} \text {. }
$$




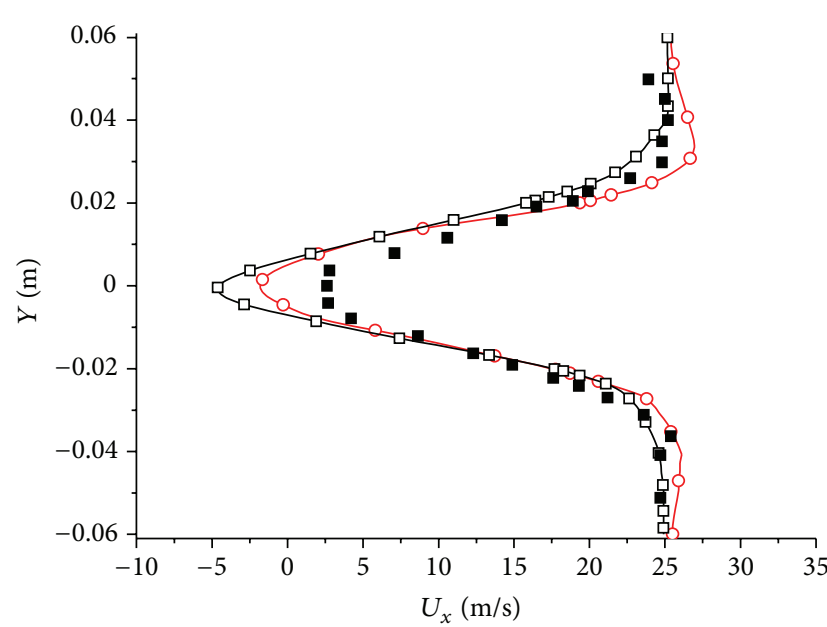

- Experiment date

$-\infty$ - 3D

$\rightarrow-2 \mathrm{D}$

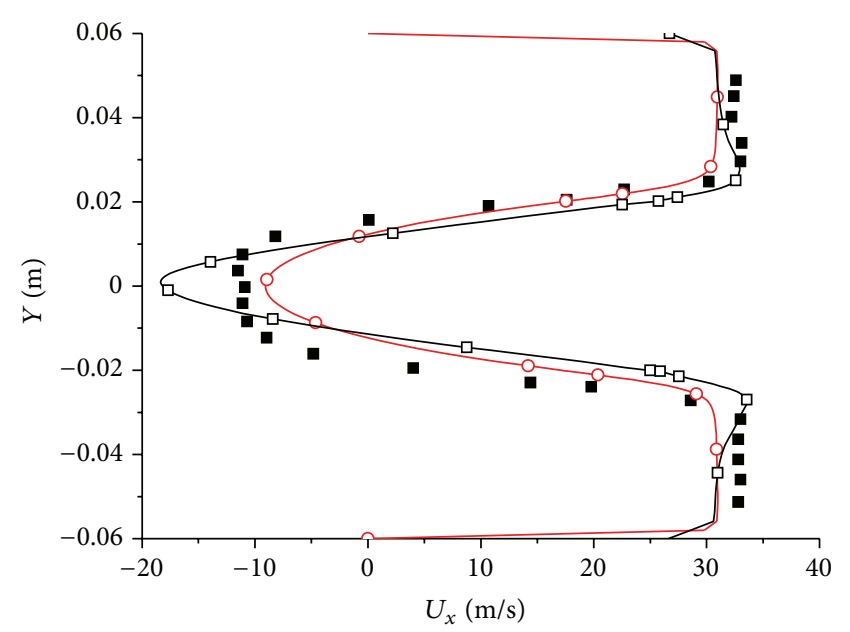

- Experiment date

$\rightarrow-3 \mathrm{D}$

$\rightarrow-2 \mathrm{D}$

(a) Nonreactive case

(b) Reactive case

FIGURE 3: Comparison of streamwise velocity profiles with experimental data $(X=6.1 \mathrm{~cm})$.

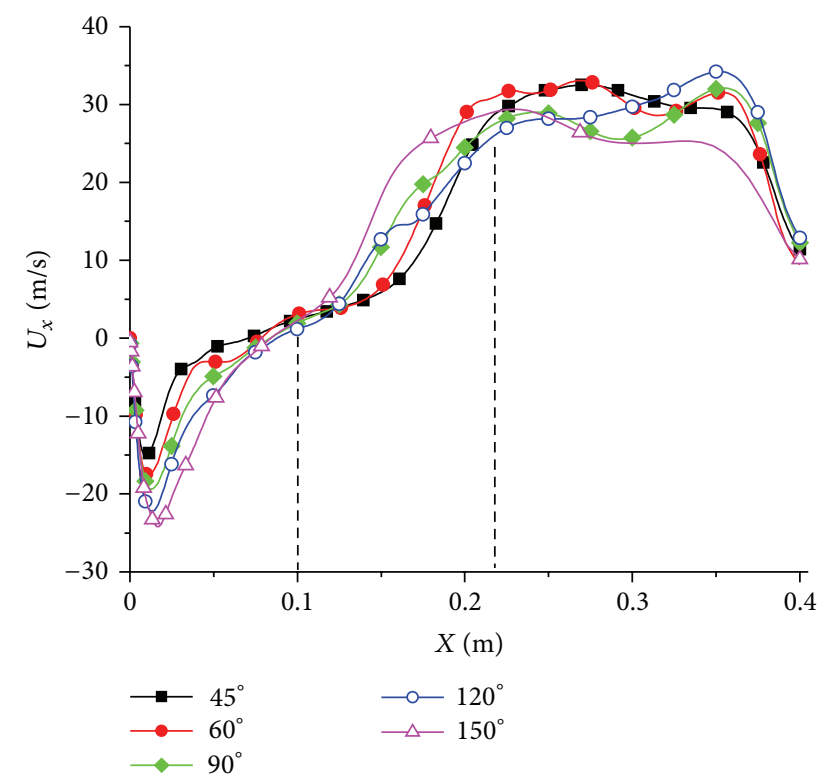

FIGURE 4: Mean streamwise velocity distribution along the center line for nonreactive case.

\section{Test Case Description and Computational Details}

3.1. Case Geometry and Boundary Conditions. Volvo Aero Corporation (VAC) Triangular Bluff Body Stabilized Combustion rig VR-1 [8] has been extensively researched both in terms of experiments and theoretical treatment, and one case of VR-1 has been used in this paper. The flow field size is shown in Figure 1. The air and propane mixture is

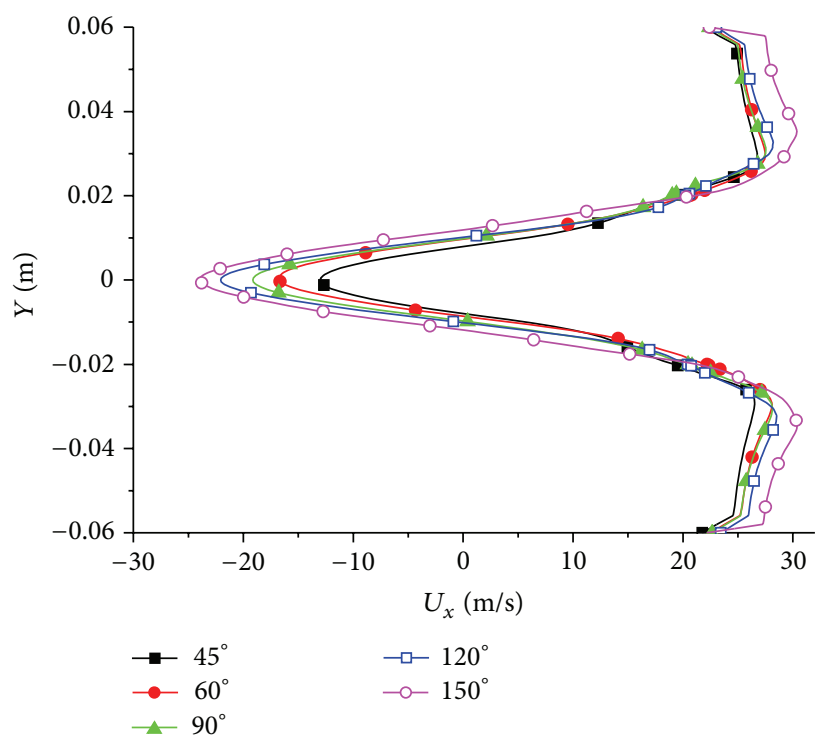

FIgURE 5: Mean streamwise velocity profiles at $X=1.5 \mathrm{~cm}$.

introduced at an equivalence ratio $\Phi=0.65$, the air mass flow rate is $0.6 \mathrm{~kg} / \mathrm{s}$, the inlet temperature is $288 \mathrm{~K}$, and the mixture velocity at channel inlet is about $17.2 \mathrm{~m} / \mathrm{s}$. The nominal pressure is $1 \mathrm{~atm}$. The Reynolds number based on the bluff-body dimension and the inlet velocity is nearly 50.000.

The governing equations are solved using CFD software ANSYS FLUENT 6.3.2.6. The mass flow inlet and pressure outlet boundary conditions are used. The mass flow rate, total temperature, and species mass fractions are assumed fixed while pressure was extrapolated at inlet. Outlet pressure 


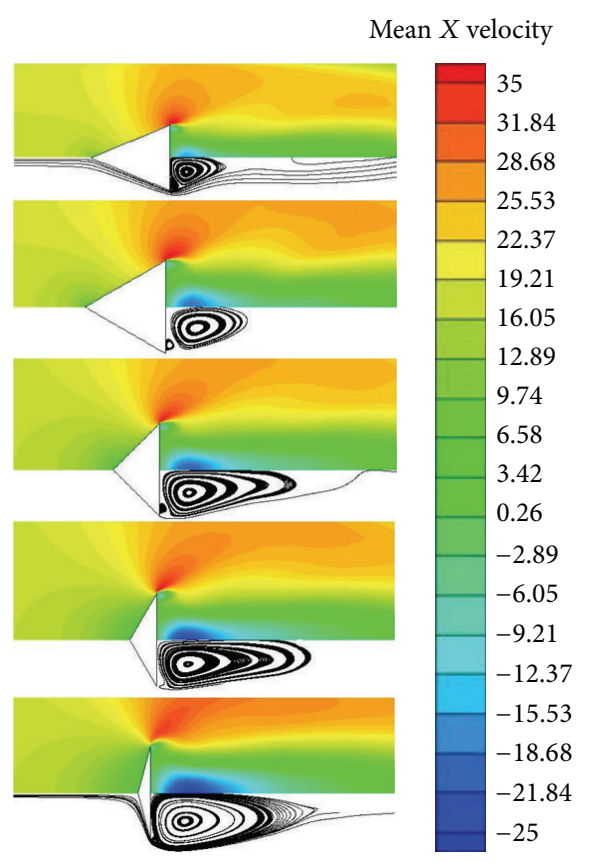

FIGURE 6: Time average streamline and streamwise velocity distribution at different $\alpha$.

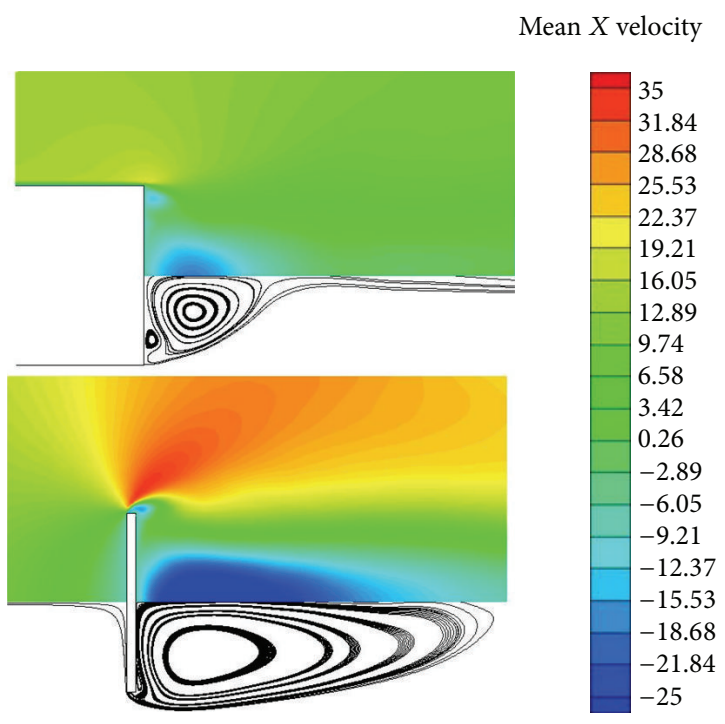

FIGURE 7: Time average streamline and streamwise velocity distribution at two limit conditions.

was $1 \mathrm{~atm}$. No slip and zero normal velocity conditions are imposed at the side and bluff body wall. The flow field of different apex angle is solved in $2 \mathrm{D}$ and also been compared with $3 \mathrm{D}$ result at $\alpha=60^{\circ}$. The finite-volume scheme is implicit, second order in time, and second order upwind in space. The integration time step of LES nonreactive field is

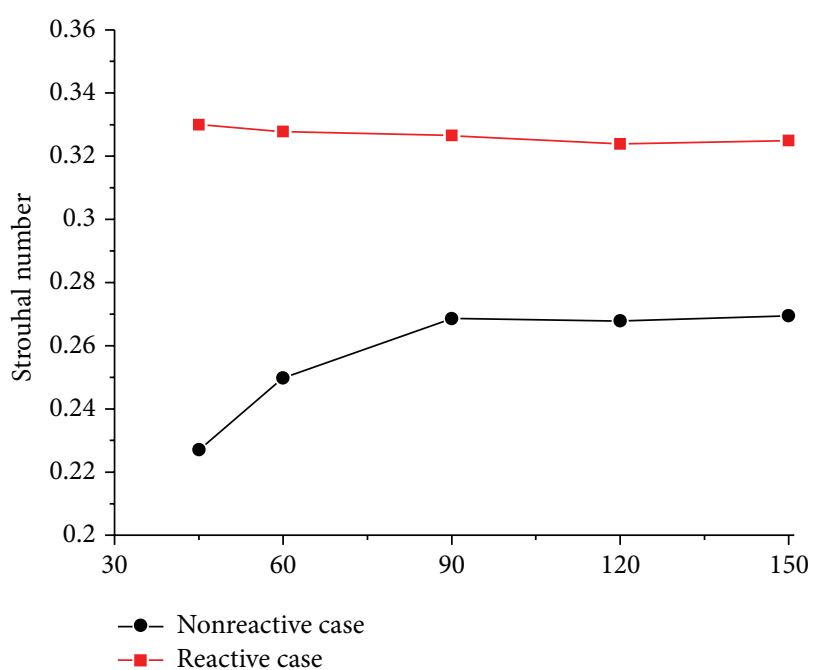

FIGURE 8: Strouhal number against apex angle for nonreactive and reactive case.

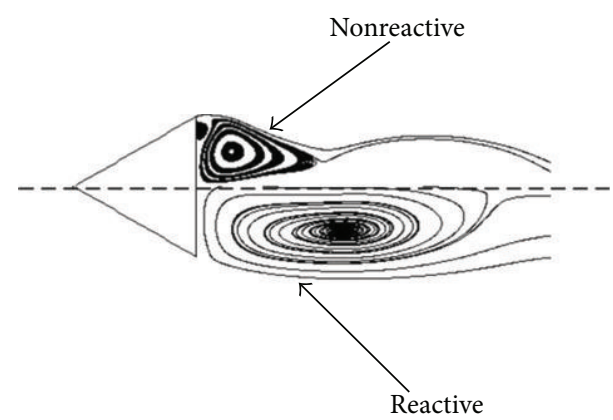

FIGURE 9: Comparison of the time average streamline distribution of $=60^{\circ}$.

set to $1 \mathrm{e}-04 \mathrm{~s}$, and $8 \mathrm{e}-05 \mathrm{~s}$ for reactive field. In this paper LESSmagorinsky model has been used. Both nonreactive and reactive flow fields have been calculated and compared. When staring the reactive calculation, the nonreactive result is used as an initialization value. In LES simulation when the flow filed becomes stable, 20 characteristic periods of the flow are sampled for plotting time-mean results.

3.2. Grid-Dependent Learning and Verification. It is important and necessary to carry out grid-dependent study for determining the optimal grid with a good balance of accuracy and speed; on the other hand, LES model needs more grid than RANS model, especially near the walls. The hexahedral grids ranged from approximately 30.950 cells to 71.267 cells are created by ICEM 11.0; the grids near bluff wall are refined which ensures the $y+$ values no larger than 2 . Three grid size options are shown in Table 1 , and the temperature distribution of different grid size cases at $X=15 \mathrm{~cm}$ is shown in Figure 2. After examining the results with different grid sizes, it is found that the optimal grid size is approximately 71.267 cells. 


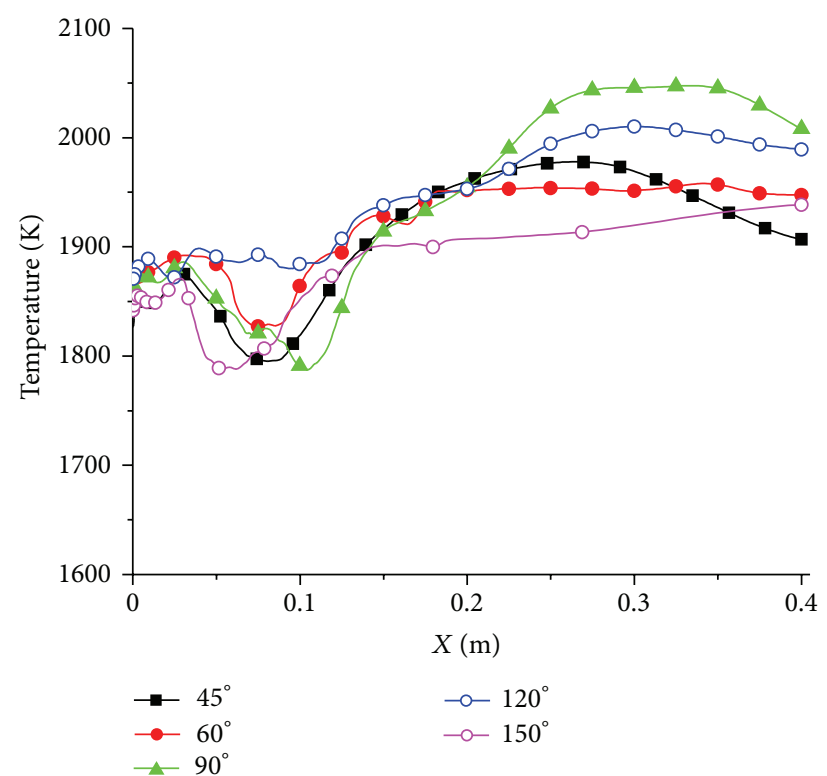

(a) Centerline

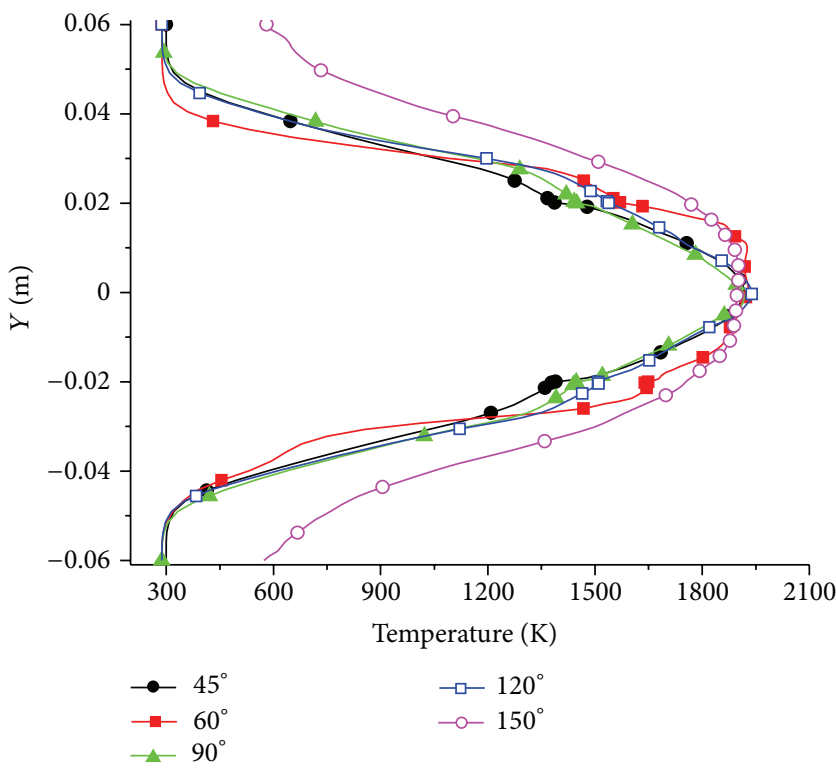

(c) $X=15 \mathrm{~cm}$

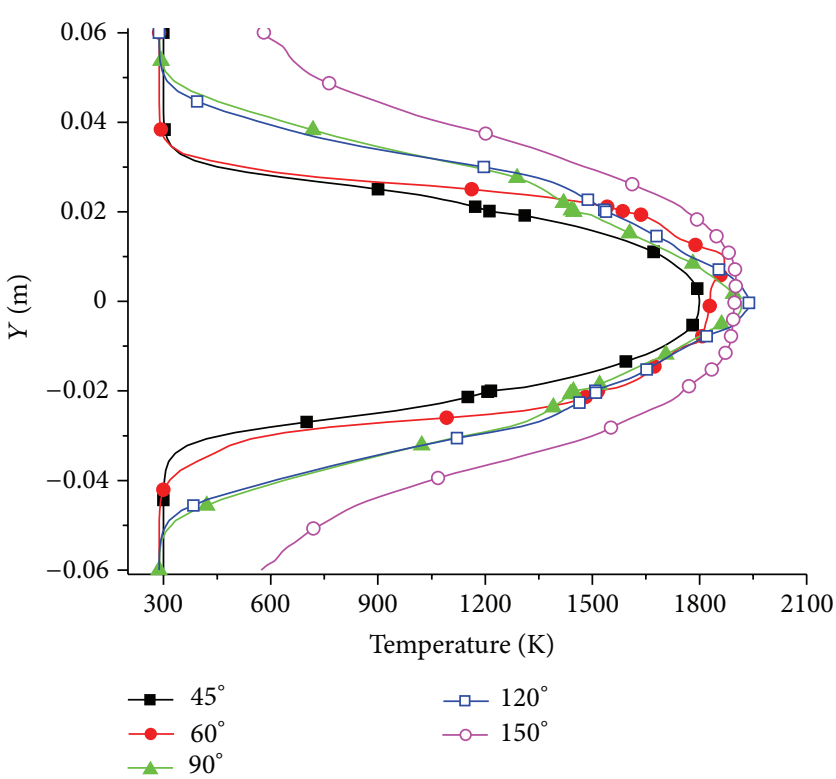

(b) $X=7 \mathrm{~cm}$

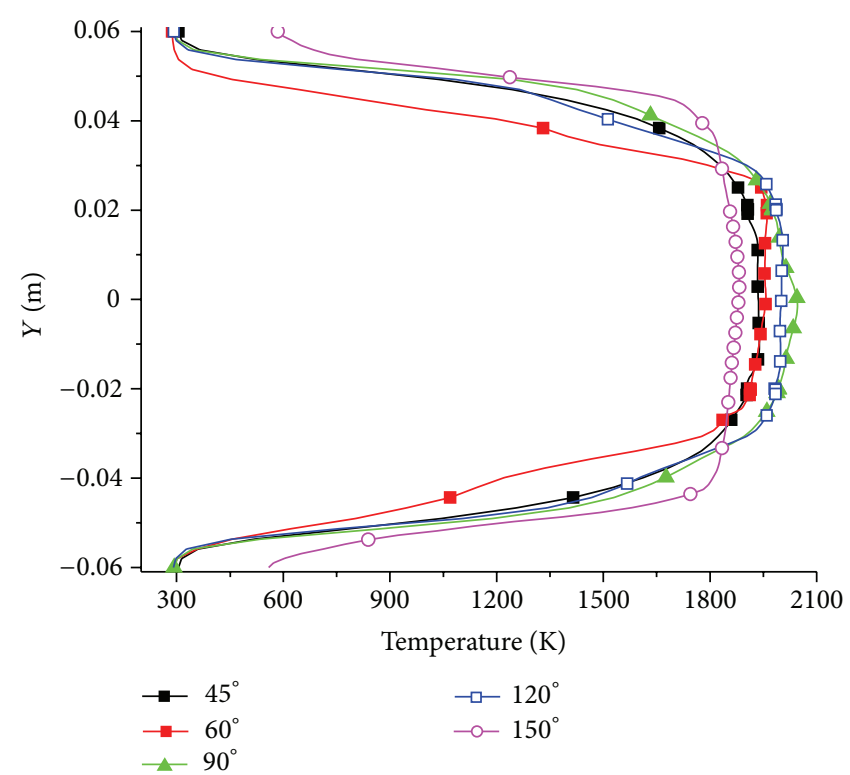

(d) $X=35 \mathrm{~cm}$

FIgURE 10: Time average temperature distribution at different location.

Although there are many studies on flow field using 2D LES problem such as flow past a cylinder or premixed bluff body flame, and 2D LES method could also provide important results as 3D model for basic research, it is important to find out dissimilarity between $2 \mathrm{D}$ and $3 \mathrm{D}$ models in order to understand difference between numerical simulation and actual result better. So the comparison between $2 \mathrm{D}$ and $3 \mathrm{D}$ (about 800.000 cells) model has been carried out in this section. From Figure 2 it can be seen that, at low temperature zone, the numerical result agrees well with experiment date, but both $2 \mathrm{D}$ and $3 \mathrm{D}$ maximum temperatures are little higher than experiment result; this is mainly because endothermic radicals reactions are missing when using one-step reaction and subgrid scale model for LES as discussed in [12]. Figure 3 shows $U_{x}$ comparisons in recirculation region $(X=6.1 \mathrm{~cm})$; it can be seen that the $U_{x}$ distributions agree well with experiment dates both in nonreactive and reactive case, but the reverse flow velocity is little higher using $2 \mathrm{D}$ model both nonreactive and reactive case. In reactive case, the curve shape is narrower than $3 \mathrm{D}$ model and experimental result.

\section{Results and Analysis}

4.1. Nonreactive Case. Figure 4 shows the mean streamwise velocity $\left(U_{x}\right)$ distribution along the center line. It is known that a recirculation region is formed because of vortex shedding; the mean recirculation zone is defined as the region 


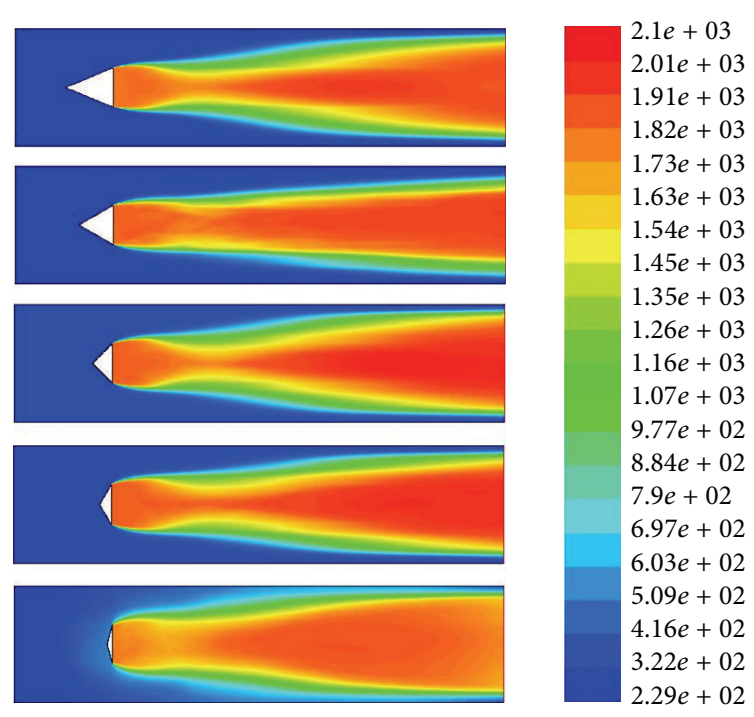

Figure 11: Contours of mean static temperature at different $\alpha$.

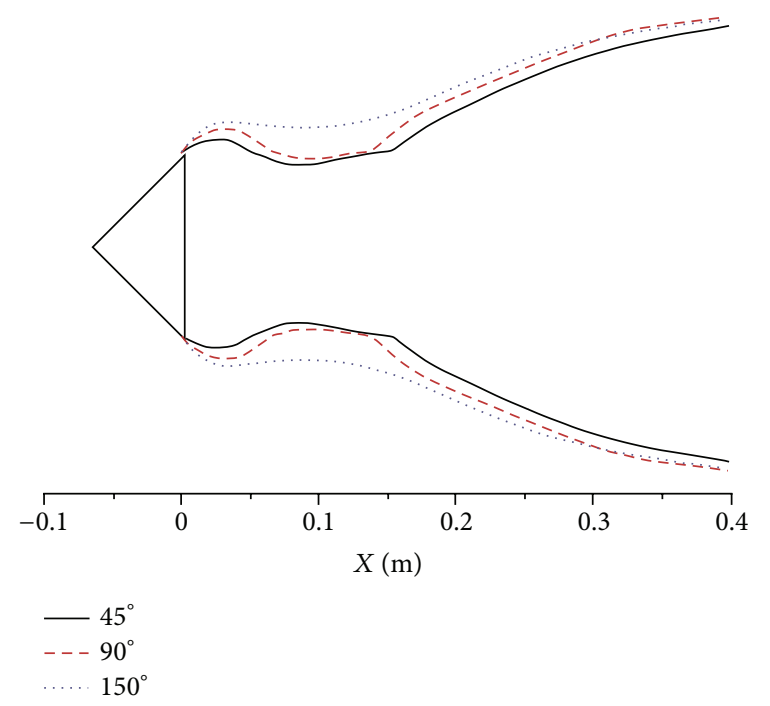

FIgURE 12: Mean flame position $(T=1400 \mathrm{~K})$ at different $\alpha$.

where the mean streamwise velocity is negative $\left(U_{x}<0\right)$. From Figure 4 it is found that as $\alpha$ is increased, the mean length of recirculation zone increases, so does the backflow velocity magnitude. Figure 5 shows the $U_{x}$ distribution at $X=1.5 \mathrm{~cm}$ (this location is in recirculation region), and as $\alpha$ is increased, the width of curve shape is increased within $Y=$ $-0.02 \mathrm{~m} \sim 0.02 \mathrm{~m}$; this means that the width of recirculation zone is increased. So according to Figures 4 and 5, it can be concluded that when $\alpha$ is increased, the recirculation zone area is increased and the backflow strength is enhanced.

From Figure 4, it can be seen that there are two critical points near $X=10 \mathrm{~mm}$ and $X=22 \mathrm{~cm}$ (marked by dash line), which divide $U_{x}$ distribution into two parts: before $X=$ $10 \mathrm{~mm}$ it is recirculation zone, and as $\alpha$ increases the backflow velocity is increased after $X=10 \mathrm{~mm}$ and before $X=22 \mathrm{~cm}$,
TABLE 1: Grid dependence-learning cases.

\begin{tabular}{lcccc}
\hline Grid size & $x$ nodes & Node bluff & $\begin{array}{c}\text { Maximum } \\
\text { mean } \\
\text { temperature }\end{array}$ & \% Difference \\
\hline (1) 30,950 & 250 & 40 & 1902.5 & - \\
(2) 47,627 & 300 & 50 & 1860.4 & 2.2129 \\
(3) 71267 & 350 & 60 & 1850.8 & 0.51609 \\
\hline
\end{tabular}

as $\alpha$ increases; the $U_{x}$ of $150^{\circ}$ is bigger than other cases, but when $X>22 \mathrm{~cm}, U_{x}$ is decreased as the flow develops, and $150^{\circ}$ is lower than other cases, this is because the recirculation zone will make the transverse flow losses increase. The bigger recirculation zone, the more flow losses, and the flow losses will affect the streamwise velocity and make $U_{x}$ of $150^{\circ}$ that is the lowest case after $X<22 \mathrm{~cm}$.

Figure 6 shows the time-average streamlines after the bluff body, and it can be seen that when $\alpha$ is increased, the recirculation area increases. The increases of $\alpha$ (decrease of base angle) mean that the angle between flow direction and base edge of bluff is increased; two limit conditions can be assumed: $\alpha$ tends to $0^{\circ}$ and $\alpha$ tends to $180^{\circ}$; when $\alpha$ tends to $0^{\circ}$, the flow mechanism near bluff base edge may correspond to the flow around a long square with angle of attack (AOA) close to $0^{\circ}$, and when $\alpha$ tends to $180^{\circ}$, the flow mechanism near bluff base edge may correspond to the flow around a very thin plate with AOA close to $0^{\circ}$; when the fluid flow past a thin plate, the rebound effects of wall are much stronger than long square, so the recirculation zone becomes bigger as Figure 7 shows.

In Figure 8 Strouhal number results in nonreactive and reactive are given. The Strouhal number is defined as

$$
\mathrm{St}=f \cdot \frac{h}{U_{\text {in }}},
$$

where $h=4 \mathrm{~cm}, U_{\text {in }}=17 \mathrm{~m} / \mathrm{s}$, and $f$ is the vortex shedding frequency, which is calculated through fast Fourier transform. For nonreactive case $\left(\alpha=60^{\circ}\right)$, St-2D is 0.252 and $3 \mathrm{D}$ is 0.249 (experiment result is 0.25 [12]); for reactive case, St-2D is 0.37 and $3 \mathrm{D}$ is 0.364 . It can be found that as $\alpha$ increases, St increases in nonreactive cases but is almost unchanged in reactive cases. According to many scholars results about flow past body $[20,21]$ that St will be increased when Re is higher, higher Re means a bigger recirculation zone, so it can be learned that if Re is unchanged, a bluff body which has a bigger recirculation zone that will have a higher St. As Figure 6(a) shows when $\alpha$ is increased from $60^{\circ}$ to $90^{\circ}$, the recirculation zone length increases more than $45^{\circ}$ to $60^{\circ}$, so the sudden increase of St of nonreactive case is easily explicable.

4.2. Reactive Case. The reacting simulations were carried out using the same numerical methodology and mesh utilized for the nonreacting simulation. Therefore, any changes in fluid dynamics can be attributed to the heat release from the combustion model described earlier. The dynamics of the reactive flow can be interpreted as due to coupling between vortex 


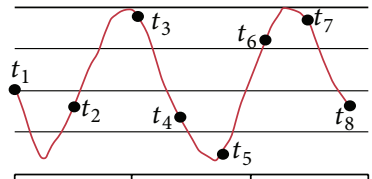

(a)
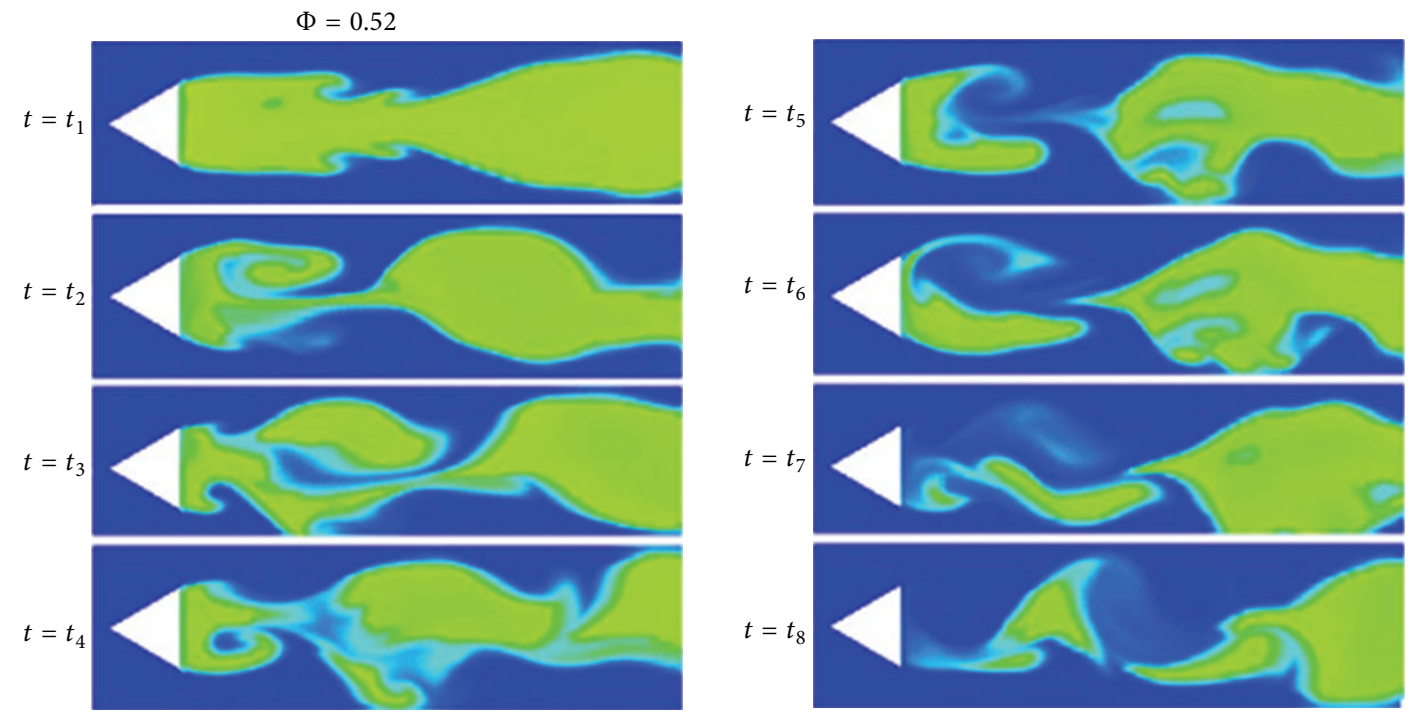

(b)

Figure 13: Time sequence of instantaneous temperature fields at the lean blow-out condition carried out by [18].

shedding and excitation of acoustic oscillations produced by heat release [18]. Comparing the nonreacting case and the reactive case, it is evident that combustion extended the recirculation region further downstream as Figure 9 shows. It was observed that in the instantaneous flow fields the asymmetric von shedding of coherent vortices no longer exists in the reacting case. Therefore, the reacting case does not possess any large-scale mixing mechanisms which typically reduce the recirculation zone length [18]. Mehta and Soteriou [22] attributed this absence of asymmetric von Karman shedding for reacting conditions to the dilatation effect of the heat release. They also found that baroclinic vorticity augments the impact of dilatation, but its effect is secondary. The recirculation zone is longer and broader in the reactive case, meaning a more gradual dissipation of momentum in the wake region with respect to the nonreactive case, and St is higher than nonreactive as Figure 8 shows.

Three typical locations are selected in order to discuss the temperature distribution against $Y$ coordinate after the bluff; the three typical locations are $X=7 \mathrm{~cm}$ (in the recirculation zone), $15 \mathrm{~cm}$ (after recirculation zone), and $35 \mathrm{~cm}$ (near the outlet). Figure 10(a) shows the temperature distribution along the centerline at different $\alpha$, it is found that case $90^{\circ}$ has a large temperature fluctuation, the minimum mean temperature is about $1780 \mathrm{~K}$, and the maximum temperature is close to $2050 \mathrm{~K}$. Figures 10 (b)-10(d) show the temperature distribution of three typical locations at different location.
It can be found from Figure 10(b) that as $\alpha$ increases, the maximum temperature is almost unchanged, but the temperature distribution curve becomes wider and $150^{\circ}$ is wider than other cases in recirculation zone; the wither curve means that the reaction area in $Y$ directions is more bigger. This is because the recirculation zone becomes bigger as $\alpha$ increases, the turbulence and flow pulsation are enhanced (see Section 4.1) which will make the combustion more efficiently. As the flow and reaction develop towards outlet, $150^{\circ}$ is also the widest case (Figures 10(c) and 10(d)). When near the outlet the maximum temperature of $150^{\circ}$ is little lower than other cases, this is because the streamwise velocity becomes lower which makes the turbulence fluctuation weak, and the flame temperature decreases near the outlet as $\alpha$ is increased.

The curve shape difference means different flame shape. Figure 11 gives the mean static temperature contour at different $\alpha$, and Figure 12 summarizes the comparison between three typical conditions of flame shape $(T=1400 \mathrm{~K})$. There is a minimum width position of the flame shape, and it can be seen that $\alpha$ has a strong effect on temperature distribution and flame shape: as $\alpha$ is increased, the minimum width of flame shape increases and the heat release increases. This means that, at the same inlet condition, the bigger $\alpha$, the higher combustion chamber volume heat release rate (VHRR). VHRR is equal to the total release heat to burning chamber volume. A higher VHRR indicates that, to release the equal heat, smaller 
combustion chamber is needed, which is very important for shortening the length of chamber in aircraft using a bluff body to stable the flame [23]. On the other hand, the effects of the turbulence are generally advantageous for the efficiency of the combustion since turbulence enhances the mixing of component chemical species and heat, but adverse effects upon combustion can also occur if the turbulence level is sufficiently high to create flame extinction. In turn, combustion may enhance the turbulence through dilatation and buoyancy effects caused by the heat release; the flame temperature is lower, the heat release is reduced which will make the flame unstable. According to Kim et al. [18] 's study, in a flame lean blow-out process the temperature distribution discontinuity first happens at the position where the flame is narrowest as Figure 13 shows, so it can be conjectured that the wider flame is more stable than narrow flame, so $\alpha=150^{\circ}$ is more stable than lower $\alpha$ cases.

\section{Conclusions}

LES simulation based on Smagorinsky subgrid scale and EDC combustion model of a premixed bluff body flame is carried out in this paper; different apex angle effects on both nonreactive and reactive flow field have been discussed. The results obtained may be summarized as follows.

(1) The recirculation zone area increases as apex angle is increased.

(2) Combustion of the fluid could extend the recirculation region length. When apex angle is increased, St increases in nonreactive case, but decreases a little in reactive case. St of reactive case is higher than nonreactive case.

(3) A bigger apex angle makes the flame shape wider, increases chamber volume heat release, and enhances the flame stability.

\section{Acknowledgments}

This work was supported by Scientific Research Fund of Hunan Provincial Education Department under Grant no. 12B023. It is also supported by National Natural Science Foundation of China (nos. 61204039 and 61106029) and Scientific Research Foundation for Returned Scholars, Ministry of Human Resources, and Social Security of the People's Republic of China.

\section{References}

[1] H. B. Ebrahimi, "Overview of gas turbine augmenter design, operation, and combustion oscillation," in Proceedings of the AIAA/ASME/SAE/ASEE 42nd Joint Propulsion Conference, AIAA Paper no. 2006-4916, pp. 5658-5673, July 2006.

[2] A. Prasad and C. H. K. Williamson, "The instability of the shear layer separating from a bluff body," Journal of Fluid Mechanics, vol. 333, pp. 375-402, 1997.

[3] S. Fujii, M. Gomi, and K. Eguchi, "Cold flow tests of a bluffbody flame stabilizer," Journal of Fluids Engineering ASME, vol. 100, no. 3, pp. 323-332, 1978.
[4] L. J. Yue, B. J. Liu, and M. L. Yang, "Study on the nearwake flow behind EBMC flameholder," Journal of Engineering Thermophysics, vol. 22, no. 2, pp. 261-264, 2001.

[5] Y. Nakamura, "Vortex shedding from bluff bodies and a universal strouhal number," Journal of Fluids and Structures, vol. 10, no. 2, pp. 159-171, 1996.

[6] D. R. Cuppoletti, J. Kastner, J. Reed, and E. J. Gutmark, "High frequency combustion instabilities with radial V-gutter flameholders," in Proceedings of the 47th AIAA Aerospace Sciences Meeting including the New Horizons Forum and Aerospace Exposition, AIAA Paper no. 2009-1176, January 2009.

[7] A. Sjunnesson, C. Nelsson, and E. Max, "LDA measurements of velocities and turbulence in a bluff body stabilized flame," Laser Anemometry, vol. 3, pp. 83-93, 1991.

[8] A. Sjunnesson, P. Henriksson, and C. Löfström, "CARS measurements and visualization of reacting flows in a bluff body stabilized flame," in Proceedings of the AIAA 28th Joint Propulsion Conference and Exhibit, AIAA Paper no. 92-3650, Nashville, Tenn, USA, July 1992.

[9] P. Siewert, Flame front characteristics of turbulent lean premixed methane/air flames at high-pressure [Ph.D. thesis], Poznan University of Technology (PUT), Poznań, Poland, 2006.

[10] P. Eriksson, “The Zimont TFC model applied to premixed bluff body stabilized combustion using four different RANS turbulence models," in Proceedings of the ASME Turbo Expo: Power for Land, Sea and Air (GT '07), pp. 14-17, Montreal, Canada, May 2007.

[11] U. Engdar, P. Nilsson, and J. Klingmann, "Investigation of turbulence models applied to premixed combustion using a level-set flamelet library approach," Journal of Engineering for Gas Turbines and Power, vol. 126, no. 4, pp. 701-707, 2004.

[12] E. Giacomazzi, V. Battaglia, and C. Bruno, "The coupling of turbulence and chemistry in a premixed bluff-body flame as studied by LES," Combustion and Flame, vol. 138, no. 4, pp. 320335, 2004.

[13] P. Wang, Large Eddy simulation of turbulent swirling flows and turbulent premixed combustion [Ph.D. thesis], Lund Institute of Technology, Lund, Sweden, 2005.

[14] C. Fureby, "Large Eddy Simulation of combustion instabilities in a jet engine afterburner model," Combustion Science and Technology, vol. 161, no. 1-6, pp. 213-243, 2000.

[15] I. Porumbel and S. Menon, "Large Eddy simulation of bluff body stabilized premixed flame," in Proceedings of the 44th AIAA Aerospace Sciences Meeting, AIAA Paper no. 2006-152, pp. 18081824, January 2006.

[16] R. R. Erickson and M. C. Soteriou, "The influence of reactant temperature on the dynamics of bluff body stabilized premixed flames.," Combustion and Flame, vol. 158, no. 12, pp. 2441-2457, 2011.

[17] N. S. Park and S. C. Ko, "Large Eddy simulation of turbulent premixed combustion flow around bluff body," Journal of Mechanical Science and Technology, vol. 25, pp. 2227-2235, 2011.

[18] W. W. Kim, J. J. Lienau, P. R. Van Slooten, M. B. Colket, R. E. Malecki, and S. Syed, "Towards modeling lean blow out in gas turbine flameholder applications," Journal of Engineering for Gas Turbines and Power, vol. 128, no. 1, pp. 40-48, 2006.

[19] B. F. Magnussen, "On the structure of turbulence and a generalized Eddy dissipation concept for chemical reaction in turbulent flow," in Proceedings of the AIAA 19th Aerospace Sciences Meeting, St. Louis, Mo, USA, 1981. 
[20] A. Venugopal, A. Agrawal, and S. V. Prabhu, "Influence of blockage and upstream disturbances on the performance of a vortex flowmeter with a trapezoidal bluff body," Measurement, vol. 43, no. 4, pp. 603-616, 2010.

[21] A. Venugopal, A. Agrawal, and S. V. Prabhu, "Influence of blockage and shape of a bluff body on the performance of vortex flowmeter with wall pressure measurement," Measurement, vol. 44, no. 5, pp. 954-964, 2011.

[22] P. G. Mehta and M. C. Soteriou, "Combustion heat release effects on the dynamics of bluff body stabilized premixed reacting flows," in Proceedings of the 41st AIAA Aerospace Sciences Meeting, AIAA Paper no. 2003-0835, 2003.

[23] S. J. Shanbhogue, S. Husain, and T. Lieuwen, "Lean blowoff of bluff body stabilized flames: scaling and dynamics," Progress in Energy and Combustion Science, vol. 35, no. 1, pp. 98-120, 2009. 


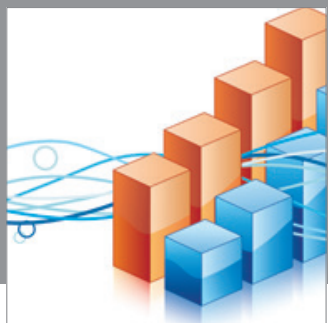

Advances in

Operations Research

mansans

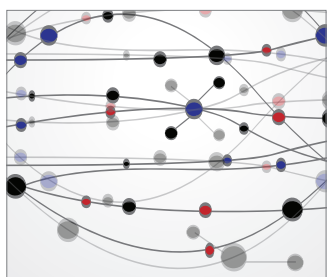

The Scientific World Journal
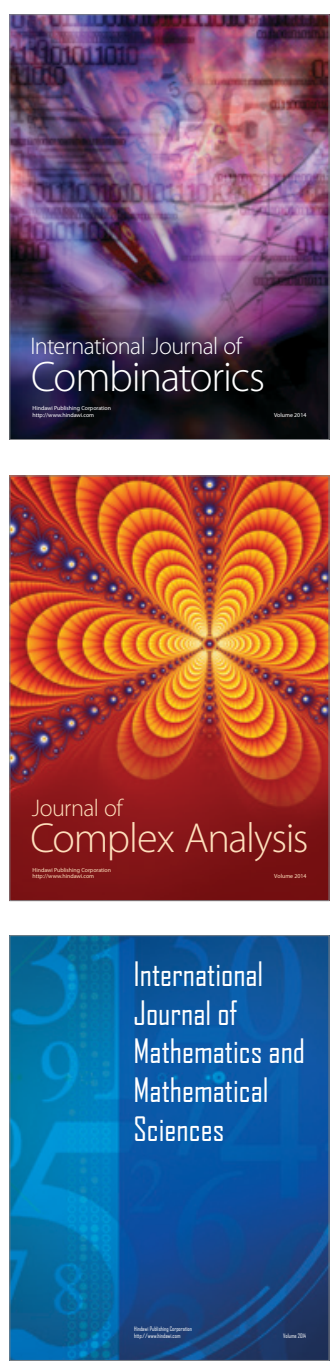
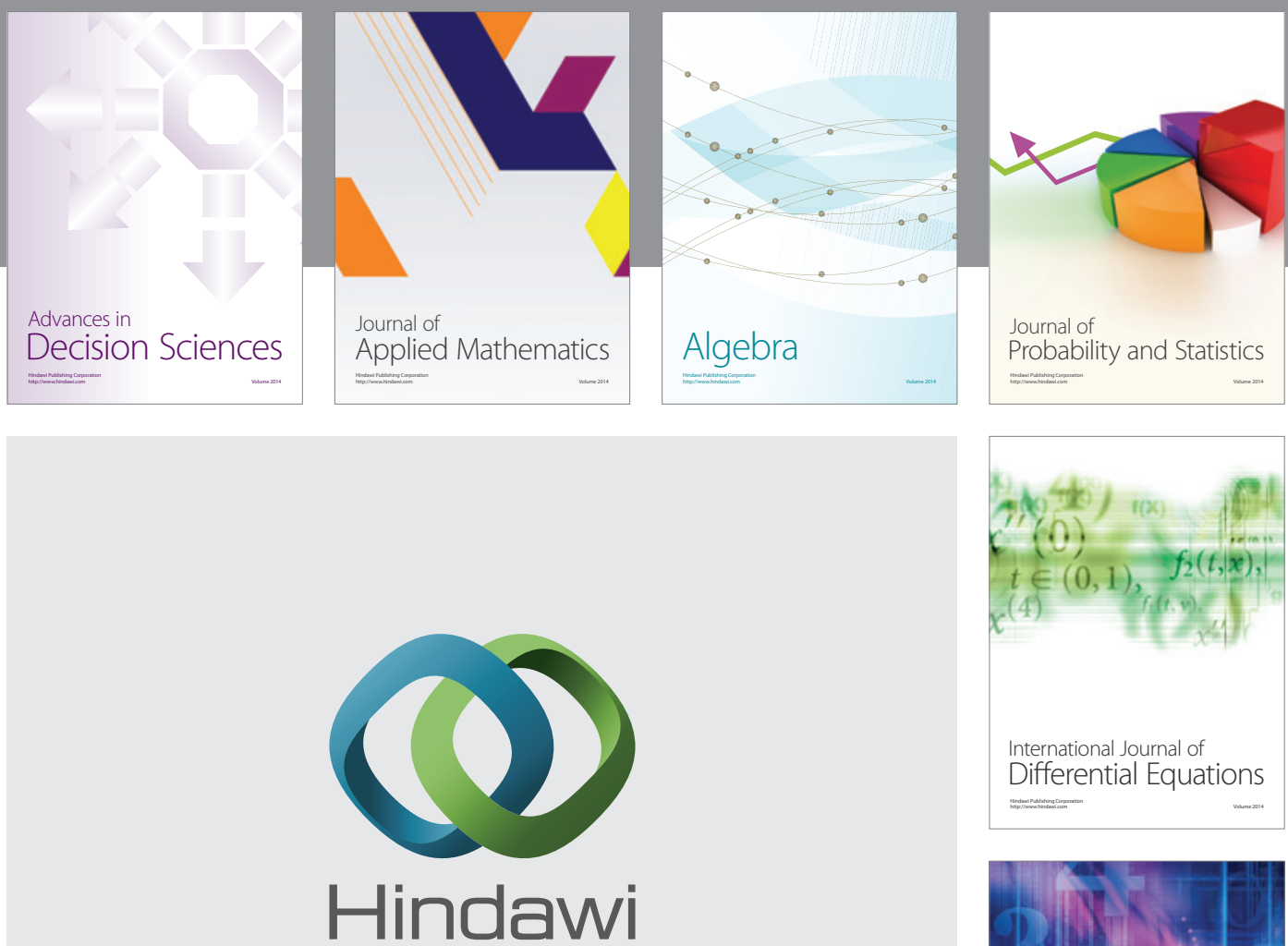

Submit your manuscripts at http://www.hindawi.com
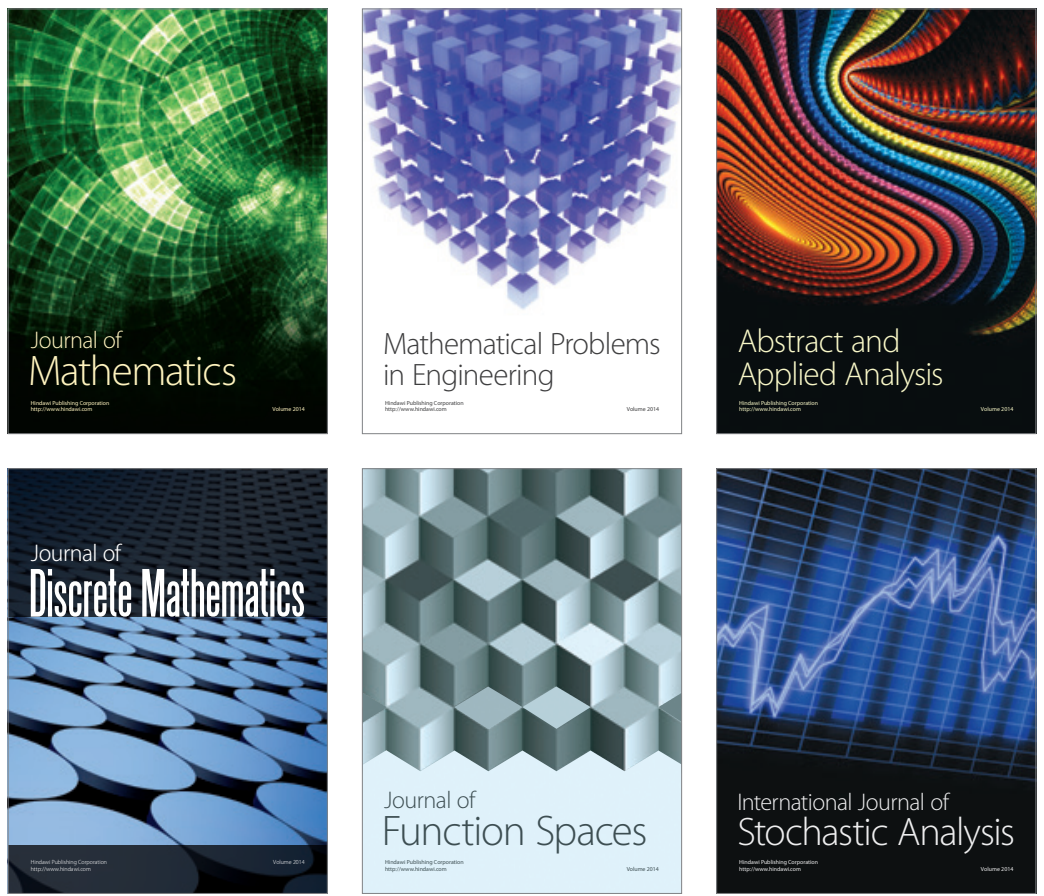

Journal of

Function Spaces

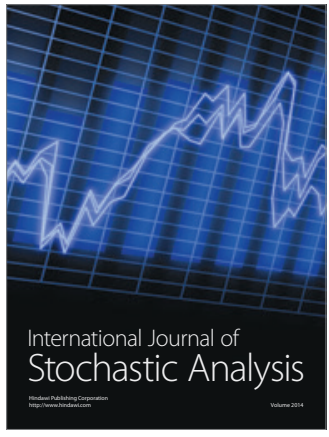

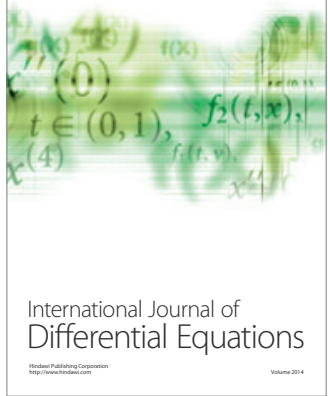
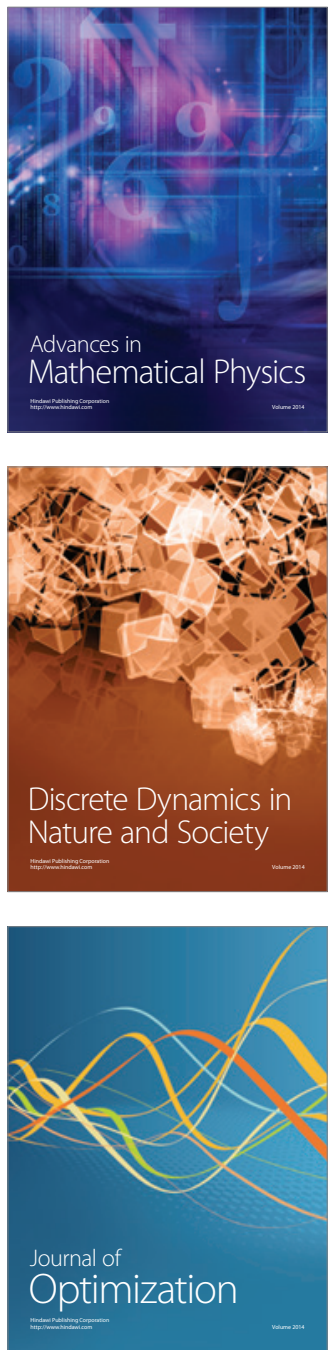